\title{
Creative Innovative Higher Education of Researchers with Flexible Skills and Synergy of Cooperation
}

\author{
Evgeniy Bryndin* \\ International American Academy of Education, Russia
}

*Corresponding author: Evgeniy Bryndin, International American Academy of Education, Russia.
Received Date: November 09, 2018

Published Date: December 19, 2018

\begin{abstract}
The concepts "creative activity", "creative abilities", "creative education" are already widely used both in western, and in the Russian scientific thought today and have innovative contents. Innovations have creative force: high novelty and usefulness and also provide competitive advantages and successful corporate activity in the market in the long-term period. Creativity has various forms: scientific (opening); technical (inventions); economic (business); social (relations with people); political (public administration); educational (cultivation of innovators). For training orientation to creative innovative approach of the higher education which ideally has to reveal, support and develop the creative potential of each personality is productive, growing up multi and between disciplinary researchers on fundamental subject knowledge, especially mathematicians - the queen of sciences. Within multi disciplinary approach communications of the studied subject domains come to light. As a result there are cross-disciplinary researches. As a result of cross-disciplinary researches new disciplines appear. To accelerate process of innovative cultivation the field and between disciplinary researchers and also to increase synergy of their cooperation, the advanced digital technologies will help.
\end{abstract}

Keywords: Creativity; Education; Innovations; Researches; Synergy

\section{Introduction}

Now an industrial era in the developed countries is replaced by an era of innovative development when the major role is played by knowledge, high technologies and new developments. National innovative systems which purpose - creation of the economy based on innovations are created. Innovative processes cover economy, the social sphere, policy, education, science, the equipment, production, business and other spheres. In innovative society the major role in his development is played by the new ideas and innovations. At an innovative stage of development information and knowledge become objects of creative thinking which product are the new ideas having big social and economic effect. At the same time upon transition to a new stage all achievements of the previous stages remain and develop at higher level. Creativity in the developed countries becomes continuous practice and the main source of competitive advantage. Practically any area of production is won finally by the one who has creative potential. Sources of creativity are creative people and the organizations. A problem of higher educational institutions to train experts of the future. Today modern education realizes the strategy of the human capital.

\section{Modern creative formation of russia}

Creative education strengthens the positions in Russia as formation of innovative type which main orientation is formation of creative thinking, development of creative abilities and intellectual potential, search of new approaches in the solution of modern problems. Creative education has the potential for creative self-development, self-determination and self-realization of the personality. These provisions find reflection in the national educational initiative of development of innovative higher education defining development of the creative person and cultivation of the innovators capable to continuous creative self-development, selfimprovement as a problem of paramount importance. Creative education is focused on development of creative abilities of the person, on fixing in his professional consciousness of installation on an innovation by transformation of knowledge and abilities 
into development potential. It is science and art of creative training. It directs to study creatively, to become creators itself and creators of the future. It expands the range of vision of problems of development and design of versions of their decision. It has to be glavkny in activity of the modern researcher and provide him success in competition at changes of an ekonokmichesky environment in processes of acceleration of technological progress in time. In creative education the most complex and productive method is training by action which is carried out in the form of the solution of real professional tasks, the analysis and playing of concrete situations, joint activity of educational group, independent work. It interrupts the fundamental, hi-tech, prospecting practical (advancing), continuous, individual variable, design and innovative education, raising research innovative potentiate the modern innovator. Creative innovative education promotes a solution of the problem of professional readiness of the experts demanded by labor market capable to set the innovative speed in social and economic development. Modern creative education is effectively organized. The main thing in the organization of creative education is the choice of disciplines, formation of educational groups, individual load of listeners or students, health-saving and also forms, quantity and distribution of practical actions.

\section{The choice of disciplines}

possibility of independent formation of the obrazokvatelny program or participation in her formation has big snatching in creative education. Today the student or the listener is almost deprived of an opportunity and motivations of deeper judgment of the sposobnoksty, educational requirements and the business career. Still sukshchestvut dictatorship of educational institution of the gosukdarstvenny standard which rigidly establishes a nakbor of obligatory disciplines. Higher education institutions have to pass to training in disciplines in the free choice and train innovators for the solution of perspective tasks. Organizational actions for differentiation of process of training in individual educational programs with an ispolkzovaniye of the technologies of training fixing a creative trace of the accumulated competences of inventive practice of innovations thinking by the student are for this purpose necessary. Creative traces of students allow employers to select shots for innovative development of the companies and to control to Higher Education Institutions training for business under the order.

\section{Creative higher education}

Is a new type of education for preparation multi and between disciplinary researchers. It treks but high qualification of teachers and motivation of creativity of students at first to multi, and then to boundaries to disciplinary innovation researches. For a crossdisciplinary research of development of vital spaces skills ecological, economic, social and others the field of disciplinary researches are necessary [1]. For a cross-disciplinary research of global wellbeing skills the field of disciplinary researches of national, individual, spiritual, social, economic and healthy wellbeing are necessary [2].

\section{Formation of educational groups}

An important point in creative education. How the group is created, establishment of the siciliano-psychological atmosphere of search, creativity, cooperation, integration of intellectual potentials depends. The educational group has to be on-stage performance group.

\section{Individual load}

Of the listener and teacher of an oriyenktirovana on formation of professional creative consciousness which assumes assimilation of knowledge from positions of identity, prospects further a razviktiya, understanding of a profession, the system of values. It assumes realization of a certain intensity of an osvokeniye of courses, immersions in their perspective, a rhythm of educational process, practical motivation of depth of knowledge and understanding of their problems.

\section{Creativity development control}

Forms of control can be also dolzhkna various: written works, testing, interview, examination tests, multi and boundaries disciplinary researches. It is necessary to otseknivat the volume, completeness, systemacity, stability, an instrumentalnost (an opportunity to use), depth of knowledge and abilities.

\section{Activization of independent work}

Of students is extremely important factor of increase in degree of creativity of educational process. She is carried out by means of realization of several the interconnected tasks

a. Increase in activity of students and their interest in process of knowledge, personal interest in study and creativity, formation of need for receiving and independent search of new knowledge, encouragement of manifestations of activity and an initiative, formation of steady positive motivation to cognitive, research and creative activity, development of need for creative self-realization and self-improvement, education of independence in them to development of evidential base.

b. Creation of conditions for active inclusion of pupils in all types of creative activity, opportunities to put knowledge into practice, involvement of students to many disciplinary research and scientific work, creation and granting conditions for manifestation of an initiative in cross-disciplinary research and scientific work.

c. Development of skills and methods of self-organization of students in on-stage performance research groups.

\section{Pragmatism of training}

Approach of training to practice, establishment of close ties between theoretical knowledge and real, everyday practical life. First, the practical organization of knowledge, granting to each student an opportunity to realize their usefulness, to understand why they are necessary, to present how they will help to solve real vital problems. Secondly, establishment of deep substantial communications between the acquired knowledge and real, practical life. Thirdly, assimilation and fixing of the most generalized, intrinsic methods of creative activity united in a universal creative method, instilling of skills and abilities of the productive decision versatile vital including informative, contradictions and the conflicts that opens a possibility of transfer of the acquired knowledge and their application in any new and unfamiliar conditions. Fourthly, 
mastering students practical skills and also such concrete heuristic means and receptions as brainstorming, a method of focal objects (a method of search of the new ideas and characteristics of an object on the basis of establishment of associative communications with other objects or their signs) and control questions. Fifthly, formation at students of ability to carry out the responsible choice and to make independent effective decisions on the basis of monitoring and analytical researches.

\section{Use of the latest information technologies}

And technical means of training. Wide and effective use of the worldwide information network "Internet". Introduction of system of distance learning. Use of audio and video of the equipment. Use of online courses and ample opportunities of computer interactive technologies.

Health saving principle: The attitude towards health of participants of pedagogical process as to basic supreme value. Health has to be considered by society as the priority value, the purpose, result and a necessary condition of successful activity of all participants of educational process. Formation at students of endurance, emotional steadiness, mental stability, ability to lead a healthy lifestyle.

Motivation of creative education: Each of types of education relies on certain motivators. Can be them: the professional status confirmed dipklomy, requirement of intellectual development, realization of individually abilities, the enriching communication with experts, professional ambitions, the need for knowledge and skills of modern professionally activity (knowledge of language, knowledge of the computer and so forth), "thirst of opening", "fashion" of a pas education. Of course, all these factors work in total. In fact, the real person always gives something a predpokchteniye, any of these factors is priority, prepotent, pronounced. Action of factors of motivation can be operated in educational processes, leaning on an essence and content of creative education. For example, it is possible to carry out obuchekny without issue of the diploma, to check not knowledge, but type of a professional myshkleniye, to estimate not the point of view, but her argumentirovanpost, to encourage not correctness of conclusions (decisions), but their practical efficiency.

\section{Psychological aspect of creativity}

Identification of new regularity or essence begins with a vychuvstvovaniye her soul in an environment in which she is shown, and about which are saved up feeling knowledge. Vychuvstvovany new regularity or essence goes the acquired skills. After mental reflection of new essence, consciousness determines it by knowledge elements. The creative innovative vychuvstvovaniye reveals new entities, communications, dependences and regularities of processes and the phenomena. The feeling - knowledge of new regularity or essence is fixed in memory. Further new creative knowledge in the course of individual thinking is developed. The psychological aspect of disclosure of creative abilities is very important for accumulation of experience of development of imagination, intelligence, ingenuity, self-training and creative innovative activity.

\section{Creative innovative higher education increases innovative synergy}

[3-18]. First, scientific and educational synergy of preparation of creative shots for creative activity. Secondly, social and economic synergy of achievement of economic stability of healthy activity. Thirdly, financial and organizational synergy of development of the economic environment. Fourthly, design and innovative synergy of integration processes in innovative activities for development of scientific and technical, technological, production, investment and personnel potential; and also increase in productivity of work, improvement of structures and competitive capacity of productions. Fifthly, industrial and technological synergy of technologies and the industry for fundamental reorganization of labor market and formation of the effective principles of work of economic system. Sixthly, health - ecological synergy health of saving of the nation and ecological development of vital spaces. Seventhly, increase in synergy of transnational communication.

\section{Creative Formation of the University of a Digital Era}

\section{Creative aspects of education}

a. The university of a digital era lays the fundamental foundation of knowledge, especially on mathematics - queens of sciences.

b. Each student has a possibility of individual hi-tech education and acquisition of skills of design with world-class competences. The identity to each participant of education at the university provides his choice to a trajectory of training and acquisition of practical skills.

c. The university is focused on training of competent experts for the companies working at the global markets.

d. The university provides professional and enterprise competences to each student in digital economy.

\section{Management of development of the digital university}

The main aspects of the environment on development of the digital university are: formation of the enterprise structures of the university capable to become engines of innovative development; development of mechanisms of effective interaction of the university with business on commercialization of knowledge and projects; training for innovative economy with use of the best foreign practices; creation at the university of the enterprise centers directed to implementation of innovative projects and attraction business - community for their financing; assistance to distribution of the best practician of implementation of joint partner projects; development of the international partner relations of the university with the leading foreign universities for the purpose of strengthening of integration of the Russian science and education into the international innovative community and also as key players of the national clusters promoting a contact to the international partners and the international markets.

\section{Educational system}

The educational system includes schools of sciences; university programs of fundamental education and discipline; the 
personalized trajectories of training and development; hybrid form of education (online + offline); educational program of healthy activity; the platform decisions simplifying communications; a digital complex of training in the research market focused activity and digital economy.

\section{Scientific directions}

a. Fundamental education on natural and to the humanities.

b. The professional focused cross-disciplinary hi-tech training in digital platforms, the industries 4.0, to clever factories, on the basis of the directions of the road map of NTI in the technological directions.

c. Hi-tech education - the most effective way of a raising of competitiveness of graduates, and in the investigation and a raising of competitiveness of high-tech industries. Such decision gets to current problems of the industry of education.

\section{Approaches to training}

a. $50 \%$ of time of training in fundamental and basic disciplines and $50 \%$ of professional practice.

b. Ontogenesis approach to fundamental training at a basis of three criteria and seven principles. Fundamental education helps development of the theory; has system effect; helps innovations, estimates development tendencies.

c. Creative approach to diversification of individual preparation on the basis of online and elective courses. Such decision is perspective for creativity development.

d. Scientific multidisciplinary and cross-disciplinary research.

e. Business - practical works.

\section{Technological monitoring}

Important function of hi-tech training is monitoring of level of the innovative competition, a condition of labor market and hi-tech productions, for the purpose of correction of process of education on digital training:
a. Digital services and applications.
b. ICT of modules.
c. Platform technologies.
d. Cognitive robotization [11-14,17].
e. Advanced digital innovations.

\section{Formation of healthy activity}

Development of the human capital as main resource of the country and key factor of development of modern economy tends to growth of life expectancy and healthy activity. Now it is about extension of healthy activity for 30-40 years, and a new level, there will be 120 years. Training of students and the population in a healthy lifestyle will solve this problem. For this purpose, the university needs to provide: a. Acquisition of competences on a healthy lifestyle.

b. Formation of family and public culture of a healthy lifestyle [15-16].

\section{Arts education}

There is a risk that spiritually not mature creative innovators can take away from a true peaceful righteous life. Arts education has to form human qualities and learn:

1. Not to bring the evil to the world not to generate the conflicts and not to infect others, not to lead mankind to disaster.

2. To extinguish angrily kind at all levels of the organization of society and to make moral history of good.

Criterion of the truth is practice. The good and evil are spiritual and moral category. On the basis of researches of spiritual and moral practice of good of history of mankind the general criterion of good is elaborated: creation and preservation of peaceful just activity. Activity by the general criterion of good will create just peace qualities of citizens. People carry out just peaceful activity on conscience.

The maintenance of arts education, forms just peace consciousness of people of secular society. Just peace qualities of citizens will develop the spiritual and moral culture of activity in society [6].

\section{Improvement of quality of life}

Improvement of quality of life is carried out by training in the healthy lifestyle, harmonious development of vital spaces, to ecological and social measures of improvement of quality of life directed to harmonization of public life and activity of the person and improvement of his wellbeing, health and life [1-2].

\section{Digital complex of training}

a. The automated information and computer technology of an individual trajectory of training at domestic and international digital platforms. She stores all trajectories of training and their results which are available to all students, both positive, and negative.

b. The educational technologies aimed at the development of creative abilities. The technology of educational process defines emergence in consciousness of the person of certain communications and interactions of knowledge, their ranging, their practical importance in concrete situations.

c. University educational platforms of distance learning and others, such as I Spring, UCHI.PRO, Mirapolis Learning Management System, Get Course, Moodle, Yo-STADI, Autor, Eliade my, Forma LMS, Dokeos, ILIAS, Opigno, OLAT.

d. University educational platforms of online courses and others, such as Courses Arzamas, Lektorium, Universalism, Khan Academy, Coursera, Academy, Open education, Universiality, Theory and practice, Lecture hall, Business Learning. 
e. Digital educational platforms unite in the "ecosystems" interconnected, based on data exchange, covering the educational directions of world level.

f. Hardware of open applied laboratories.

g. Ecosystem of generation of the new ideas and design teams.

h. The system of real time scale for interactive multimedia training and teleconferences in development of digital economy [9-10].

\section{Risks of Creative Approach in Education}

Creative education is risky for pupils. At the exit of brazovatelny process a certain percent of creative people in whose fate the moments favorable for development of their creative abilities have happily met turns out. It is necessary to develop and use more successfully the educational technologies contributing to the development of creative abilities of pupils and students and to form a basis of strategy of creativity in education where much attention will be paid to personal development of young people for preparation them to innovative activity in new century. Now the problem of realization of creative capacity of society for preservation and strengthening of the predominating positions in global space is very accurately realized. This direction has acquired special relevance on a wave of scientific, technological and economic break in the last decade. New century will turn into an era of big intellectual fight which participants is predetermined to become today's students. This fact it is essential demands development of creative innovative education. The cult of creative study contributes to the continuous creative development of the personality on intensive intra-corporate programs of training and in Higher Education Institutions, in training of the house and in everyday life [19].

Kreaivny people change innovatively quicker than technologies. Creative individualization leads to growth of innovative offers. There is a problem of future employment of creative innovators. They will be educated generations, and they should start their career from considerably excellent set of competences, then to their predecessors. Creative innovators apply for jobs which provide increase in labor productivity and competitive capacity. They have to create the market of high-performance competitive innovative work. Generation of the inventors having experience of practical work in science, technologies, engineering and mathematicians have to define the global future effectively.

\section{Acknowledgement}

None.

\section{Conflict of Interest}

No Conflict of interest.

\section{References}

1. Evgeniy Bryndin (2018) Development of living floor spaces on the basis of ecological economic and social programs. J Resources and Environmental Economics 1(1): 1-8.

2. Evgeniy Bryndin (2018) Spiritual, Social, Economic and Healthy Aspects of Global Wellbeing. Journal the European Proceedings of Social \& Behavioral Sciences Ep SBS (38): 97-111.

3. Zhuravlev VA (2008) Creative thinking, creative management and innovative development of society. (Chast1,2) No. 4 - page 3-8, pp. 51-55.

4. Kobyak OV, Andros IA (2006) Role of innovative education in formation of creative individually economic thinking and innovative public culture.

5. Bryndin EG (2016) The strategy of the hi-tech advancing education. Collection of the International conference Management of Talents and Transformation of Corporate Culture TGU publishing house 221-224.

6. Bryndin EG (2017) Good, a love and peace - a basis of culture of harmonious society. Scientific and practical conference State, Society and Church: education and culture - as a basis of ensuring national security of Russia Sib AGS 71-74.

7. Bryndin EG (2017) Innovative development With the Support on Hi-Tech Education. International scientific and practical conference Problems of Sustainable Development of Russian Regions TyumIGU.

8. Bryndin EG (2017) Cross-disciplinary technological culture of formation of scientific and educational society. Human measurement of the university. TGU publishing house 11-15.

9. Bryndin EG (2018) Development of the digital sector of economy. Collection of the VII International scientific and practical conference: Models of the public and corporate management: traditions and prospects MSU 335-342.

10. Bryndin EG (2017) Creative management of diversification of economy. Materials V of the Tyumen international sociological Forum: Dynamics of social transformation of the Russian society: regional aspects. Tyumen State University, Russia, pp, 977-981.

11. Bryndin EG (2015) The robot With Imitative Thinking. PNIPU bulletin: Electrical equipment, Information technologies, Control systems, Perm: PNIPU 14: 5-36.

12. Bryndin EG (2016) Cognitive robots. Management of development of large-scale systems (MLSD), To YIP RAHN 2: 285-294.

13. Evgeniy Bryndin (2017) Cognitive Robots with Imitative Thinking for Digital Libraries, Banks, Universities and Smart Factories. International Journal of Management and Fuzzy Systems 3(5): 57- 66.

14. Evgeniy Bryndin (2017) Program Hierarchical Realization of Adaptation Behavior of the Cognitive Mobile Robot with Imitative Thinking. International Journal of Engineering Management 1(4): 74-79.

15. Bryndin EG, Bryndina IE (2017) Public Health Care on the basis of a healthy lifestyle. Scientific journal National Health, Kub MU 1: 34-42.

16. EG Bryndin, IE Bryndina (2017) Formation of Public Health Care on Basis of Healthy Lifestyle. International Journal of Psychological and Brain Sciences 2(3): 63-68.

17. Evgeniy Bryndin (2018) Technological Thinking, Communication and Behavior of Androids. Communications 6(1): 13-19.

18. Evgeniy Bryndin (2018) Technological, Economic and Social Aspects of Management by Development of the Digital Industry 4.0. International Journal of Managerial Studies and Research (IJMSR) 6(3): 19-30.

19. Roberts P (2006) Nurturing Creativity in Young People: A report to Government to inform future policy, London: DCMS. 